\title{
Cheminer avec Myriam David, I'amie des enfants (1917-2004)
}

La première fois que le nom de Myriam David et la spécificité de son travail m'ont interpellée a été la rencontre avec l'un de ses textes, co-rédigé avec Geneviève Appel, qui décrivait les interactions mère-enfant de trois bébés suivis dès la maternité, puis à leur retour au domicile familial. D'emblée, la finesse de l'observation, l'authenticité de l'intérêt porté à ces bébés et à leurs mères, la sympathie que suscitaient les auteurs pour ces dyades relationnelles, la limpidité du texte rendaient accessibles les données et les conclusions de l'étude, à savoir qu'on trouvait un lien incontestable entre les modalités d'expression et d'échange utilisées électivement par les mères et celles que leur bébé développait en retour. On se sentait devenu plus intelligent de l'avoir lue. Sensation d'autant plus soulageante que, dans le passage « De la pédiatrie à la pédopsychiatrie et à la psychanalyse » que j'étais en train d'effectuer, la lecture de la Psychiatrie de l'enfant, où ce texte était publié, pouvait parfois m'opposer une opacité décourageante.

J'ai rencontré Myriam David en 1979, époque où j'étais engagée dans un travail hospitalier de psychiatrie adulte et où je souhaitais reprendre contact avec la pédopsychiatrie. Rendez-vous est donc pris au Centre Alfred Binet, où vient vers moi une dame de taille moyenne aux cheveux très blancs, et au regard bleu très vif, souriant et malicieux, accueillante et chaleureuse. Après avoir fait plus ample connaissance, elle me fit l'honneur de m'inviter à venir travailler avec elle puis de lui succéder dans sa responsabilité de médecin directeur du Centre Familial d'Action Thérapeutique qu'elle avait créé, poste que j'ai occupé durant les vingt années qui suivirent, de 1979 à 1999.

Très vite, j'ai découvert ses qualités humaines et intellectuelles : bienveillance et intégrité, rigueur et humour, tolérance et exigence, ouverture sans dogmatisme et, par-dessus tout, simplicité, modestie, attention portée à l'autre, générosité sans l'ombre d'une mesquinerie, tout cela n'excluant pas une vision réaliste du monde. À mes yeux, M. David a toujours eu le don de marier ces qualités fondamentales pouvant paraitre incompatibles.

$\mathrm{Si}$ je pense à ce qui m'a toujours le plus frappée dans sa pratique, me reviennent en tête son amour, son intérêt, son émerveillement face à tout enfant, et son attention sans faille portée au développement de l'enfant et à tout ce qui peut le favoriser, sans exclusive et sans mépris. La matérialité du quotidien, la vie du corps et la vie psychique étaient pour elle étroitement liées et méritaient le même soin et la même réflexion. Je l'ai vue passer de longs moments avec une assistante maternelle pour réfléchir à la meilleure manière d'habiller un enfant sur le point de rencontrer ses parents. Elle a ainsi été à l'origine d'une clinique et d'une théorisation qui restent révolutionnaires encore aujourd'hui, par leur manière d'intégrer dans une même pratique les données du monde matériel et celles de la vie psychique. Fondamentalement, M. David se référait à la théorie psychanalytique, à ses auteurs et à ses concepts dans son élaboration de la clinique du placement familial. Ses apports théoriques ont toujours été solidement ancrés dans la pratique qui était la sienne, et celle de son équipe, au sein de la première institution qu'elle ait créée, en 1966, pour y accueillir, au sein de familles d'accueil recrutées dans ce but, des enfants mis en danger par une vie commune avec des parents psychiquement trop perturbés pour élever leur enfant sans lui faire encourir des risques graves, d'ordre physique et psychique.

Le travail sur la séparation, dont elle n'avait pas peur, contrairement à beaucoup, car cela lui apparaissait comme le préalable indispensable d'un soin possible, a été l'une des originalités de sa réflexion et de sa pratique dont elle a tiré un livre que tous les travailleurs sociaux dans le domaine de la protection de l'enfance consultent régulièrement encore. Elle avait la capacité rare de prendre une distance intellectuelle tout en sachant s'engager affectivement et matériellement. Je l'ai vue, après une journée de travail, partir à huit heures du soir avec la psychologue référente de l'enfant, à la recherche d'une adolescente fugueuse dont elle était le médecin consultant. Elle n'était rigidifiée par aucun dogmatisme, grâce à quoi je pus venir travailler dans son institution, quoique initialement de formation psychanalytique lacanienne. Elle s'autorisait une grande ouverture : théorie de l'attachement, étude des interactions, travail avec l'observation, son fil rouge consistant dans l'attention portée à la clinique de l'enfant qu'elle ramenait régulièrement au centre du débat. "Et l'enfant? » était son maître-mot. Sensible à la souffrance de l'enfant, elle refusait d'être jugeante, en particulier vis-à-vis des parents si maltraitants fussent-ils. Elle restait pleine de compassion, ayant peut-être ramené de son expérience des camps ce questionnement qu'elle m'a parfois exprimé : « est-ce que nous savons ce que nous aurions fait à leur place, dans leur situation ?».

Elle avait le don de susciter en chacun de ses collaborateurs le meilleur de lui-même par sa bienveillante écoute et par son analyse constructive des interventions qu'on lui rapportait, de même qu'elle nous incitait à travailler avec ce qu'elle appelait la partie saine qui existe en chaque parent, si démuni soit-il.

Espérons qu'elle n'a pas emporté avec elle cette meilleure part de nous-mêmes, même si, comme chacun le ressent peu ou prou, nous sommes tous un peu orphelins aujourd'hui. Il nous reste à continuer à travailler dans le fil de sa pensée.

Hana Rottman

Psychiatre et psychanalyste, Ancien Médecin Responsable du CFAT, Association de Santé Mentale du XIII ${ }^{\mathrm{e}}$ Arrondissement de Paris. 